\title{
A COMPREHENSIVE REVIEW ON THE USE OF BACTERIOPHAGE IN MICROBIAL KILLING AND CANCER THERAPY
}

\author{
Rhea Sharma \\ Amity Institute of Biotechnology \\ Amity University, Noida, Uttar Pradesh, India
}

\begin{abstract}
As the name infers, bacteriophage is a bacterium-explicit infection. It taints and kills the bacterial host. Bacteriophages have acquired consideration as elective antimicrobial elements in the science local area in the western world since the disturbing ascent of anti-infection obstruction among organisms. Although considered as prokaryote-explicit infections, ongoing examinations demonstrate that bacteriophages can associate with eukaryotic life forms, including people. In the current audit, these collaborations are isolated into two classifications, i.e., backhanded, and direct connections, with the inclusion of bacteriophages, microscopic organisms, and eukaryotes. Conversation on bacteriophage-related illnesses, transcytosis of bacteriophages, bacteriophage connections with cancer cells, cooperation of bacteriophages and eukaryotes against bacterial contaminations, and level quality exchange among bacteriophages and eukaryotes.
\end{abstract}

Conversation on the historical backdrop of bacteriophage revelation and the early clinical investigations with phages and audit the new writing accentuating research led in Poland and the previous Soviet Union. Additionally, conversation on the reasons that the clinical utilization of bacteriophages neglected to flourish in the West, and we share our contemplations about future possibilities for phage treatment research.

Keywords - Bacteriophage, procapsid, capsid, lytic cycle, lysogenic cycle, mutualistic, microbial balance, metastasis, phage therapy.

\section{INTRODUCTION}

A bacteriophage, likewise, referred to casually as a phage, is an infection that contaminates and reproduces inside microbes and archaea. The term was gotten from "microscopic organisms" and the Greek (phagein), signifying "to eat up".

Bacteriophages are made of proteins that typify a DNA or RNA genome and may have structures that are either basic or elaborate. Their genomes may encode as few as four genes and as many as hundred genes. Phages duplicate inside the bacterium following the infusion of their genome into its cytoplasm.

Bacteriophages are among the most well-known and different elements in the biosphere. Bacteriophages are universal infections, found any place microscopic organisms exist. It is assessed there are more than $10^{31}$ bacteriophages in the world, more than each and every living being on Earth, including microbes, consolidated. Infections are the most bountiful organic substance in the water section of the world's seas, and the second biggest segment of biomass after prokaryotes, where up to $9 \times 10^{8}$ virions per milliliter have been found in microbial mats at the surface, and up to $70 \%$ of marine microorganisms might be contaminated by phages.

\section{DISCOVERY OF BACTERIOPHAGE}

Bacteriophages or phages are bacterial infections that attack bacterial cells and, on account of lytic phages, upset bacterial digestion and influence the bacterium to lyse. The historical backdrop of bacteriophage disclosure has been the subject of protracted discussions, including a debate over claims for need. Ernest Hankin, an English bacteriologist, detailed in 1896 on the presence of checked antibacterial action (against Vibrio cholerae) which he saw in the waters of the Ganges and Jumna streams in India, and he proposed that an unidentified substance (which went through fine porcelain channels and was heat labile) was answerable for this marvel and for restricting the spread of cholera pestilences. After two years, the Russian bacteriologist Gamaleya noticed a comparative marvel while working with Bacillus subtilis, and the perceptions of a few different specialists are additionally thought to have been identified with the bacteriophage wonder. Notwithstanding, none of these specialists further investigated their discoveries until Frederick Twort, a medicinally prepared bacteriologist from Britain, once again introduced the subject very nearly 20 years after Hankin's perception by revealing a comparative wonder and propelling the theory that it might have been expected to, among different conceivable outcomes, an infection. Nonetheless, 


\section{International Journal of Engineering Applied Sciences and Technology, 2021 \\ Vol. 6, Issue 5, ISSN No. 2455-2143, Pages 318-326 \\ Published Online September 2021 in IJEAST (http://www.ijeast.com)}

for different reasons - including monetary challenges, Twort didn't seek after this finding, and it was an additional 2 years before bacteriophages were "authoritatively" found by Felix d'Herelle, a French-Canadian microbiologist at the Institut Pasteur in Paris.

The revelation or rediscovery of bacteriophages by d'Herelle is oftentimes connected with an episode of extreme hemorrhagic dysentery among French soldiers positioned at Maisons-Laffitte (on the edges of Paris) in July-August 1915, in spite of the fact that d'Herelle clearly first noticed the bacteriophage wonder in 1910 while contemplating microbiologic method for controlling an epizootic of locusts in Mexico. A few warriors were hospitalized, and d'Herelle was doled out to direct an examination of the episode. During these investigations, he made without bacterium filtrates of the patients' fecal examples and blended and hatched them with Shigella strains detached from the patients. A bit of the combinations was immunized into trial creatures (as a component of d'Herelle's investigations on fostering an antibody against bacterial dysentery), and a part was spread on agar medium to notice the development of the microbes.

It was on these agar societies that d'Herelle noticed the presence of little, clear regions, which he at first called taches, then, at that point taches vierges, and, later, plaques. D'Herelle's discoveries were introduced during the September 1917 gathering of the Institute of Sciences, and they were thusly distributed in the gathering's procedures. As opposed to Hankin and Twort, d'Herelle had little uncertainty about the idea of the marvel, and he recommended that it was brought about by an infection fit for parasitizing microscopic organisms. The name "bacteriophage" was additionally proposed by d'Herelle, who, as per his memories, settled on this name along with his significant other Marie on 18 October 1916 - the day preceding their youngest girl's birthday (d'Herelle evidently first segregated bacteriophages in the late spring of 1916, around 1 year after the MaisonsLaffitte episode). The name was shaped from "microscopic organisms" and "phagein" (to eat or eat up, in Greek), and was intended to suggest that phages "eat" microbes.

D'Herelle, who believed himself to be the pioneer of bacteriophages, was made mindful of the earlier revelation of Twort yet kept up with that the wonder portrayed by Twort was unmistakable from his disclosure. Meanwhile, rather than Twort, d'Herelle effectively sought after investigations of bacteriophages and emphatically advanced the possibility that phages were live infections and not "proteins" as a considerable lot of his kindred scientists thought. The need debate stopped in the long run, and numerous researchers acknowledged the autonomous disclosure of bacteriophages and essentially alluded to it as the "Twort-d'Herelle wonder" and, later, the "bacteriophage marvel."

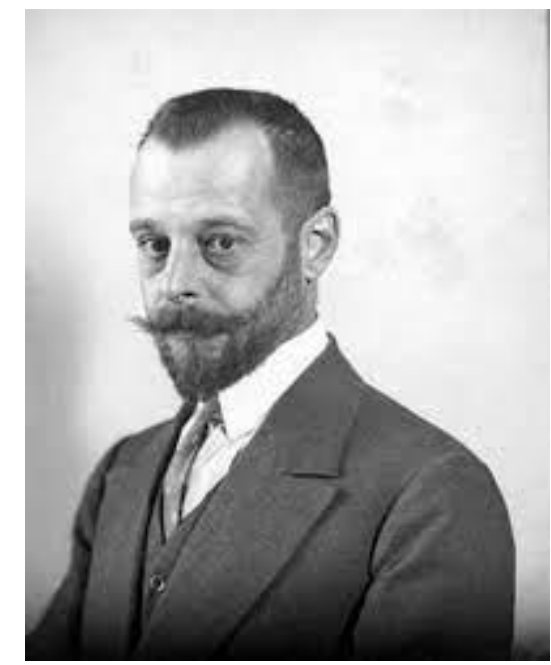

Fig. 1. Felix d'Herelle

\section{STRUCTURAL ORGANIZATION OF BACTERIOPHAGE}

Phages may have various shapes and sizes. The most examined bunch is that of followed phages with a dsDNA genome, and it additionally addresses the biggest gathering. The followed phages have three significant segments: a capsid where the genome is stuffed, a tail that fills in as a line during disease to get move of genome into have cell and a unique cement framework (adsorption contraption) at the finish of the tail that will perceive the host cell and infiltrate its divider. Cell assets are utilized for the phage propagation.

Self-get together pathway of phages: Various duplicates of the capsid/platform complex tie the entry protein to shape the procapsid; then, at that point, the framework proteins are launched out, and DNA is bundled into the procapsid, which grows to the size of the develop capsid. The head fulfilment proteins (the plug and the connector) are bound to the entryway complex forestalling DNA spillage. Then, beautification proteins tie to the capsid, and the tail, amassed independently or after DNA bundling, is appended; in this manner, the last irresistible phage is delivered.

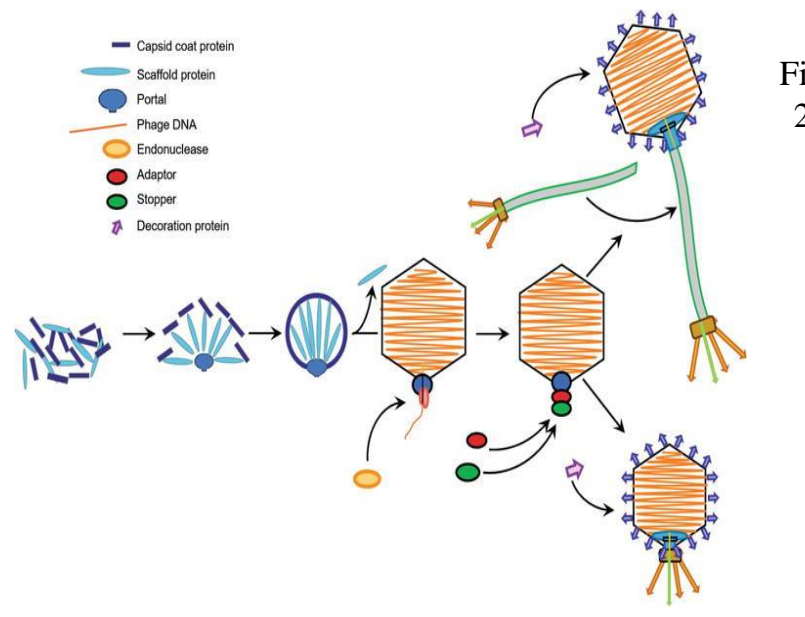

Fig.

2. 


\section{International Journal of Engineering Applied Sciences and Technology, 2021 \\ Vol. 6, Issue 5, ISSN No. 2455-2143, Pages 318-326 \\ Published Online September 2021 in IJEAST (http://www.ijeast.com)}

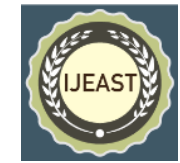

Self- assembly pathway of bacteriophage

Fig. 3. Structural organization of major capsid proteins

\subsection{PROCAPSID}

The capsid of a phage has a forerunner development, named the procapsid, during the gathering cycle. Scaffolding proteins (SPs) drive the get together cycle by overseeing major capsid protein (MCP) subunits to fabricate an icosahedral procapsid that is subsequently loaded up with dsDNA. The SPs are bound to the entryway complex during development of a procapsid with framework inside. The arrangement of conformational changes from a procapsid to the phage capsid where genome has been stuffed is named as the development interaction and goes through a progression of intermediates. A few phages like HK97 and T5 don't have a different SP; all things being equal, the capsid protein is combined with a framework space at the N-terminus. When the procapsid is collected, the framework area is cut off and afterward like the different SP will be eliminated from the capsid to account for the genome. Designs of procapsids and develop virions have been resolved for various phages. The circular capsid shell grows during development and gets slenderer because of changes in the between and intrasubunit contacts.

\subsection{CAPSIDS}

Most followed phages have capsids of an icosahedral shape framed by different duplicates of at least one protein. Icosahedral capsids are portrayed by $12 \times$ fivefold, $20 \times$ triple and $30 \times$ twofold axes, which bring about 60 duplicates of the significant free parts. A triangulation number ( $T$ number) portrays the quantity of duplicates of a similar protein inside the free piece of the icosahedral grid. The general number of proteins in the infection relates to the $\mathrm{T}$ number increased by 60; for instance, a $\mathrm{T}=3$ infection has 180 subunits. Oligomers of the proteins that are situated on the fivefold axes are alluded to as pentons, while those buildings that are situated on the essences of the icosahedron and structure oligomers from six subunits are named as hexons.

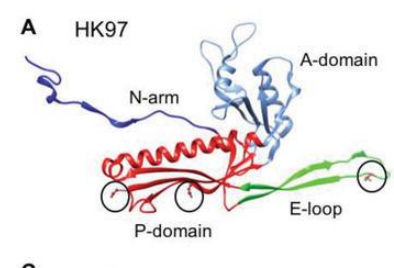

B $\varepsilon 15$

C P22
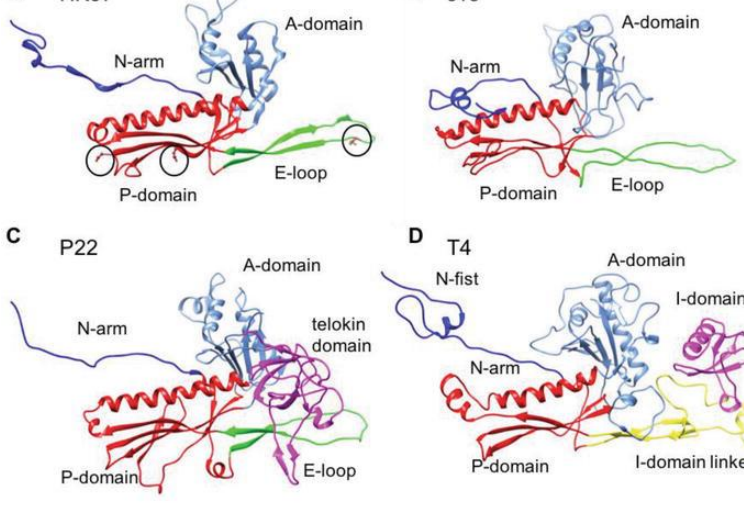

D T4

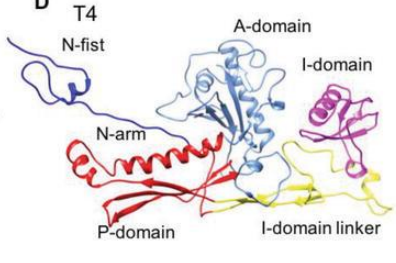

\subsection{CONNECTORS}

In phages and herpesviruses, one of the fivefold vertices of the capsid is supplanted by a head-totail interface (HTI), which is a multi-protein complex (connector). In all phages the HTI gives a stage to docking of preassembled tails in Sipho-or Myoviridae or starts the get together of a short tail in Podoviridae. The HTI contains a portal complex (PP) and head fulfilment proteins that fill in as a valve for shutting the channel and keeping the phage genome inside the capsid at high pressing factor and just opens to permit genome discharge from the capsid (under normal conditions) when the phage turns out to be firmly joined to a host cell.

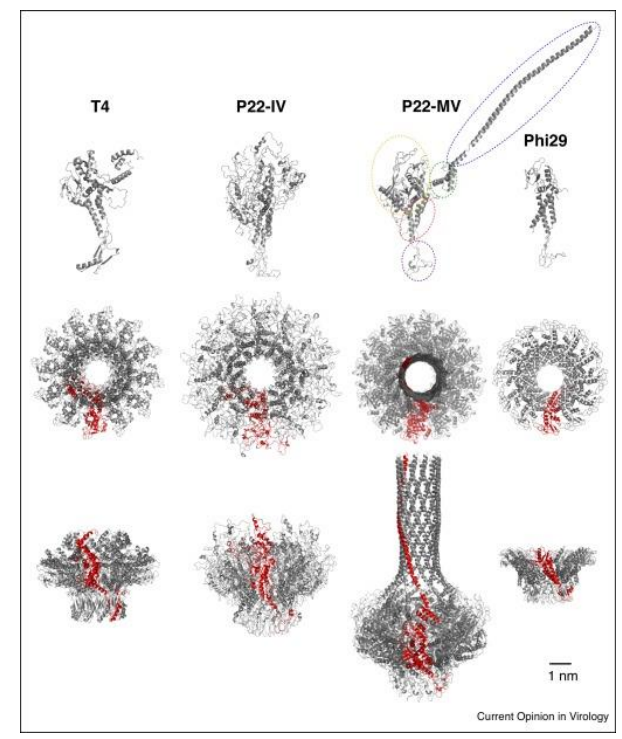

Fig. 4. Structure of portal proteins

\subsection{TAILS}

The tail association in phages relies upon their sort: Siphoviridae have long adaptable tails, and

Podoviridae have extremely short tails that for the most part comprise of the glue gadget, while Myoviridae have inflexible long contractile tails that comprise of various proteins shaping the inward unbending cylinder and the external contractile sheath. Siphoviridae and Myoviridae have an autonomous pathway for gathering of their tails and are connected to the capsid after it has been loaded with genome. Nonetheless, in Podoviridae the tails are gathered on the capsids after DNA bundling as the last advance of selfget together. The long tails of Siphoviridae are made of tail proteins (TPs) that structure roundabout oligomeric rings with three-or sixfold rotational evenness. The rings are amassed around a tape measuring protein (TMP) that characterizes the length of the tail and are stacked on the highest point of one another with helical evenness. A tail terminator protein $(\mathrm{TrP})$ covers the tail when it arrives at the 


\section{International Journal of Engineering Applied Sciences and Technology, 2021 \\ Vol. 6, Issue 5, ISSN No. 2455-2143, Pages 318-326 \\ Published Online September 2021 in IJEAST (http://www.ijeast.com)}

length characterized by the TMP; the TrP fills in as an interface with the capsid. At the point when the phage connects with the host receptor, the HTI opens and the TMP is moved out by DNA because of the inward pressing factor of the capsid. Most long tails have a smooth external surface; however some have limbs that distend outwards from the tail surface.

\subsection{ADSORPTION ASSEMBLY}

Most Siphoviridae phages have an oligomeric ring framed by distal tail proteins (DTPs), which is joined to the last ring of the tail tube. The DTP ring generally fills in as a device to perceive and interface with receptor-restricting proteins; here and there, this cooperation is helped by tail filaments found in T4, T5 and different phages. The DTP of SPP1 doesn't have the strands. Numerous phages that contaminate Gramnegative microorganisms have lysozyme-like proteins on the closures of their tails, which enter the periplasm to process the peptidoglycan boundary.

\section{LIFE CYCLE OF BACTERIOPHAGE}

During disease a phage connects to a bacterium and additions its hereditary material into the phone. After that a phage for the most part follows one of two life cycles, lytic (harmful) or lysogenic (mild). Lytic phages assume control over the hardware of the cell to make phage parts. They then, at that point annihilate, or lyse, the cell, delivering new phage particles. Lysogenic phages consolidate their nucleic corrosive into the chromosome of the host cell and reproduce with it as a unit without obliterating the cell. Under specific conditions lysogenic phages can be incited to follow a lytic cycle.

\subsection{LYTIC CYCLE}

Bacteriophages that reproduce through the lytic life cycle are called lytic bacteriophages. In the wake of tainting microorganisms with lytic bacteriophages in the lab, plaques can be seen on the petri plates. Plaques are little clear regions on the agar surface where the host microorganisms have been lysed by lytic bacteriophages. The lytic life cycle is to some degree like the useful life pattern of creature infections and comprises of the accompanying advances.

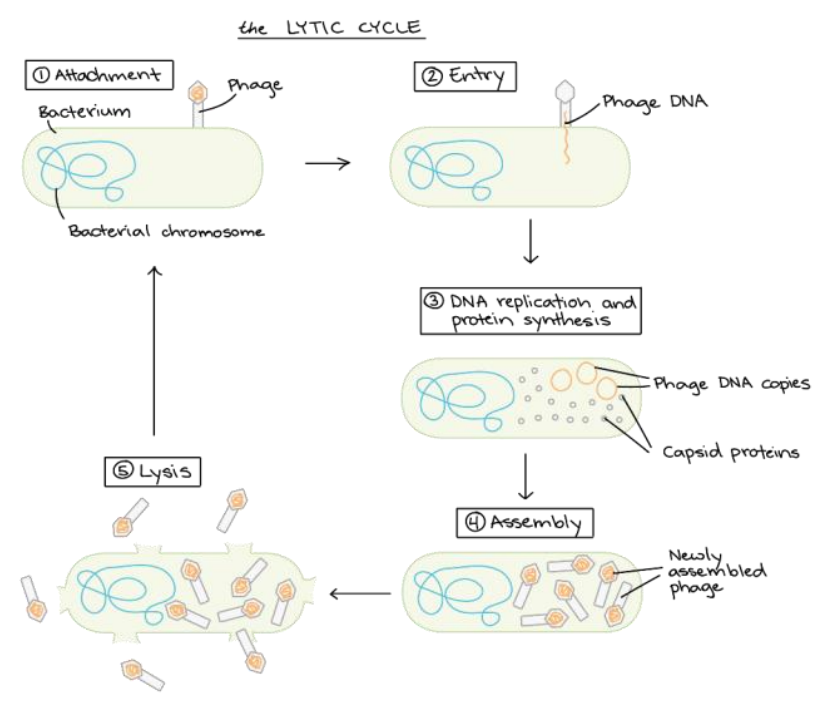

Fig.5. Lytic Cycle

\section{- ADSORPTION}

Connection locales on the bacteriophage adsorb to receptor destinations on the host bacterium.

Most bacteriophages adsorb to the bacterial cell divider, albeit some can adsorb to flagella or pili. Explicit strains of bacteriophages can just adsorb to explicit strain of host microorganisms. This is known as viral specificity.

\section{- PENETRATION}

Because of bacteriophages that adsorb to the bacterial cell divider, a bacteriophage compound "penetrates" an opening in the bacterial divider and the bacteriophage infuses its genome into the bacterial cytoplasm. A few bacteriophages achieve this by getting a sheath which drives an empty cylinder into the bacterium. This starts the overshadowing time frame. The genomes of bacteriophages which adsorb to flagella or pili enter through these empty organelles. Regardless, just the phage genome enters the bacterium so there is no uncoating stage.

\section{- REPLICATION}

Compounds coded by the bacteriophage genome shut down the bacterium's macromolecular (protein, RNA, DNA) blend The bacteriophage repeats its genome and utilizations the bacterium's metabolic hardware to orchestrate bacteriophage chemicals and bacteriophage primary parts.

\section{- MATURATION}

Capsids collect from the capsid proteins and are loaded down with DNA to make bunches of new phage particles.

\section{- RELEASE}

Late in the lytic cycle, the phage communicates qualities for proteins that punch holes in the plasma film and cell divider. 


\section{International Journal of Engineering Applied Sciences and Technology, 2021 \\ Vol. 6, Issue 5, ISSN No. 2455-2143, Pages 318-326 \\ Published Online September 2021 in IJEAST (http://www.ijeast.com)}

The openings let water stream in, causing the cell to extend and blast like a packed water expand.

\subsection{LYSOGENIC CYCLE}

In the lysogenic cycle, the initial two stages (connection and DNA infusion) happen similarly as for the lytic cycle. Be that as it may, when the phage DNA is inside the cell, it's anything but quickly duplicated or communicated to make proteins. All things being equal, it's anything but a specific district of the bacterial chromosome. Under the right conditions, the prophage can get dynamic and returned out of the bacterial chromosome, setting off the leftover strides of the lytic cycle.

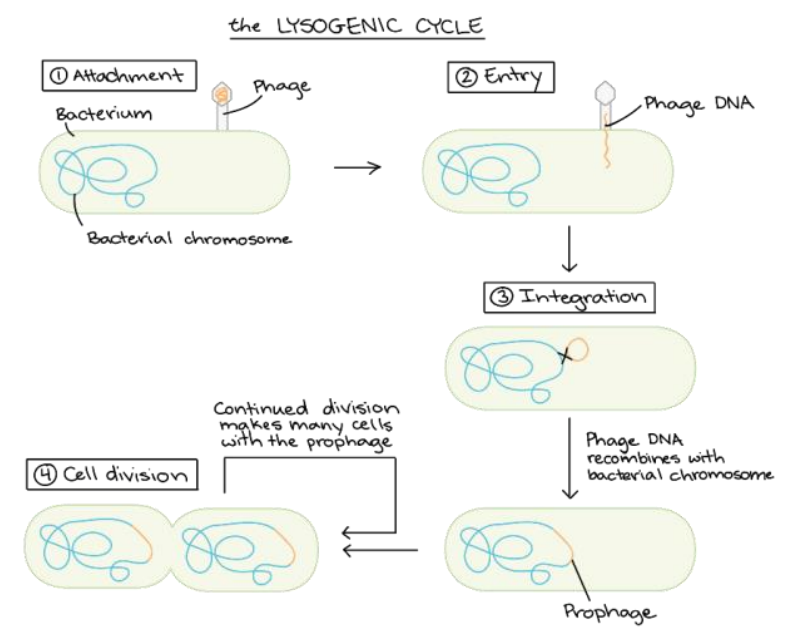

Fig. 5. Lysogenic Cycle

\begin{abstract}
- TEMPERATE PHAGE
Bacteriophages equipped for a lysogenic life cycle are named calm bacteriophages. At the point when a mild bacteriophage contaminates a bacterium, it can either recreate through the lytic life cycle and cause lysis of the host bacterium, or it can join its DNA into the bacterium's DNA and become a nonirresistible prophage.
\end{abstract}

\section{- LYSOGEN}

In the last case, the cycle starts by the bacteriophage adsorbing to the host bacterium or lysogen and infusing its genome as in the lytic life cycle. Be that as it may, the bacteriophage doesn't close the host cell. All things being equal, the bacteriophage DNA embeds or incorporates into the host bacterium's DNA.

\section{- PROPHAGE}

The coordinated phage DNA, called a prophage, isn't dynamic: its qualities aren't communicated, and it doesn't drive creation of new phages. Nonetheless, each time a host cell partitions, the prophage is replicated alongside the host DNA, getting a complementary lift. The lysogenic cycle is less gaudy than the lytic cycle, however toward the day's end, it's simply one more way for the phage to repeat.

\section{INDIRECT INTERACTIONS BETWEEN BACTERIOPHAGE AND EUKARYOTES}

\subsection{BACTERIOPHAGES ASSIST TO KILL BACTERIAL PATHOGENS OF EUKARYOTES}

The capacity of bacteriophages to kill pathogenic microbes of eukaryotes supports the resuscitated interest in bacteriophages as an elective antimicrobial treatment. The itemized components utilized by bacteriophages to help eukaryotes differ.

Bacteriophages, especially T4 bacteriophages, go about as non-have inferred insusceptibility against bacterial trespassers at human mucosal surfaces. T4 phage ties pitifully to a mucin glycoprotein, one of the fundamental structure squares of the bodily fluid (discharged by the epithelial mucosa), utilizing an immunoglobulin-like area of Hoc protein. The feeble restricting gives extra security to the epithelial cells by working with the T4 phage killing of and forestalling colonization by bacterial microbes. The frail restricting additionally augments the capacity of $\mathrm{T} 4$ phage to kill microbes by empowering it to get across mucosal surfaces in a sub diffusive style. Sub diffusive movement expands the likelihood of bacteriophage-bacterium experiences, as it permits the phage an intensive investigation of specific areas of the bodily fluid.

The event of collaborations between phages, microorganisms, and eukaryotic cells brings up the issue about the adequacy of phage treatment. A further report explored the security issues encompassing the impact of test bacteriophage treatment in vitro on the intracellular killing capacity of granulocytes and monocytes. The creators found that treatment including $\mathrm{T} 2, \mathrm{~T} 4$, and $\mathrm{A} 3$ bacteriophages doesn't influence the intracellular killing capacity of the referenced cells. A later examination in people arrived at comparative resolutions. Specifically, that bacteriophage treatment, managed as a mixed drink of a few lytic bacteriophages, doesn't influence the killing capacity of polymorphonuclear neutrophils and fringe blood mononuclear cells during constant disease brought about by pathogenic Escherichia coli, Enterococcus faecalis, $P$. aeruginosa, and $S$. aureus, paying little mind to the course of organization and contamination type. Moreover, the bacteriophage treatment worked on the killing capacity of fringe blood mononuclear cells during non-pathogenic E. coli $\mathrm{B}$ diseases in patients who reacted emphatically to the treatment. In light of these perceptions, the creators proposed that bacteriophage treatment is adequately protected to be 


\section{International Journal of Engineering Applied Sciences and Technology, 2021 \\ Vol. 6, Issue 5, ISSN No. 2455-2143, Pages 318-326 \\ Published Online September 2021 in IJEAST (http://www.ijeast.com)}

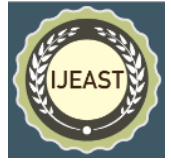

utilized in people, particularly in instances of ongoing contamination.

\subsection{BACTERIOPHAGES DISRUT THE MUTUALISTIC MICROBIAL BALANCE INSIDE THE HUMAN BOBY}

The mutualistic connection among organisms and people is viewed as fundamental for keeping up with physiological capacities and homeostasis in the human body. The relationship is significant as the human body is an asylum of almost 100 trillion microorganisms addressing a wide scope of animal categories, particularly inside the stomach related lot. The presence of bacteriophages that can kill microorganisms, including gainful microscopic organisms, may move the equilibrium towards dysbiosis (maladaptation of the microbial piece), hence setting off illnesses. At the end of the day, bacteriophages can likewise become human microbes.

As per this theory, bacteriophages might be the potential initiators of Parkinson's sickness. Parkinson's illness is set apart by the collection of misfolded $\alpha$-synuclein in dopaminergic neurons of the substantia nigra due to an exhaustion of the synapse dopamine. As per the proposed pathophysiologic pathway of Parkinson's sickness, the misfolding of $\alpha$-synuclein starts in the enteric sensory system and spreads slowly to the substantia nigra. The misfolding is believed to be the consequence of the shortfall of certain lactic corrosive microbes, Lactococcus spp., in the gut, which are answerable for keeping up with the appropriate degrees of dopamine in the enteric sensory system. L-DOPA, as a component of Parkinson's sickness drug regiment, influences the microbial populace in the gut. The examination of the faecal examples from LDOPA-guileless Parkinson's infection patients showed modification of microbiota and phageota. The gut populace of Lactococcus spp. is multiple times lower than that in control people. The exhaustion of Lactococcus spp. is related with the excess of explicit lytic bacteriophages, Lactococcus bacteriophage 936 and Lactococcus infection c2. Lactococcus bacteriophages are thought to kill Lactococcus spp., in this way advancing the advancement of Parkinson's infection.

\section{DIRECT INTERACTIONS BETWEEN BACTERIOPHAGE AND EUKARYOTES}

\subsection{BACTERIOPHAGES CAN PENETRATE AND DISPERSE WITHIN EUKARYOTIC HOST}

Bacteriophage infiltration of the eukaryotic cell could clarify the perception that bacteriophages are found in numerous multicellular eukaryotes, even in separated areas, e.g., the human cerebrum, which had been for quite some time considered sterile. This perception gives important data on the pharmacokinetic parts of bacteriophage treatment, which is essential with regards to utilizing bacteriophages as an elective antimicrobial treatment. It additionally stresses the chance of utilizing bacteriophages as vectors in medication and quality conveyance frameworks, including treatments focused on towards the mind tissue, gastrointestinal lot, and lung by means of foundational or neighbourhood conveyance. Besides, it's anything but a sensible clarification of the component of direct horizontal gene transfer (HGT) among phages and eukaryotes, talked about in a later segment.

\subsection{BACTERIOPHAGE CAN BIND TO AND HAMPER METASTASIS OF CANCER CELLS}

Examination of T4 and HAP1 phage conduct in mouse holding onto B16 melanoma cells yielded intriguing perception. It uncovered that despite having a lot more noteworthy fondness for integrin $\beta 3$ in the malignancy cells, HAP1 phage is taken out more quickly by Kupffer cells in the liver by phagocytosis than $\mathrm{T} 4$ phage. It was recommended that HAP1 is more inclined to phagocytosis on the grounds that the abbreviated form of Hoc protein doesn't cover the head capsid proteins, which are hence effectively identified by Kupffer cells. Wild type Hoc protein has four areas, three of which are like eukaryotic immunoglobulin. Domain 1 is like Fc receptors, area 2 to that of the third immunoglobulin-like space of Perlecan, and area 3 to the Vset group of immunoglobulin superfamily. Along these lines, the Hoc protein most likely developed as a type of variation of T4 bacteriophages to keep away from safe framework acknowledgment, in this manner permitting them to make due inside eukaryotes.

Study exhibited that bacteriophages T4 and M13 can stifle the declaration of HSP90 quality in human prostate disease cells (PC3), liable for the advancement of mitosis, DNA fix, and avoidance of apoptosis and autophagy. The concealment is intervened by the association of T4 and M13 phages with HSP90 receptors and results in apoptosis and autophagy of disease cells. Like GP24-integrin $\beta 3$ restricting, the specific system that advances the downregulation of the statement of the HSP90 quality after T4 and M13 phage restricting to HSP90 receptors is obscure. Notwithstanding, these discoveries feature the uncommon cooperation among bacteriophages and eukaryotes and furthermore present another way to deal with investigate the conceivable utilization of bacteriophages as anticancer specialists.

\section{PHAGE THERAPY}

\subsection{EARLY STUDIES OF PHAGE THERAPY}

Not long after his revelation, d'Herelle utilized phages to treat diarrhoea, in what was likely the main endeavour to utilize bacteriophages restoratively. The examinations were directed at the Hôpital des Enfants-Malades in Paris in 1919 under the 


\section{International Journal of Engineering Applied Sciences and Technology, 2021 \\ Vol. 6, Issue 5, ISSN No. 2455-2143, Pages 318-326 \\ Published Online September 2021 in IJEAST (http://www.ijeast.com)}

clinical oversight of Professor VictorHenri Hutinel, the medical clinic's Head of Paediatrics. The phage arrangement was ingested by d'Herelle, Hutinel, and a few clinic assistants to affirm its security prior to directing it the following day to a 12-year-old kid with serious diarrhoea. The patient's side effects stopped after a solitary organization of d'Herelle's antidysentery phage, and the kid completely recuperated inside a couple of days. The adequacy of the phage readiness was "affirmed" in no time subsequently, when three extra patients having bacterial looseness of the bowels and treated with one portion of the arrangement began to recuperate inside $24 \mathrm{~h}$ of treatment. Be that as it may, the consequences of these investigations were not quickly distributed and, in this way, the main revealed use of phages to treat irresistible illnesses of people came in 1921 from Richard Bruynoghe and Joseph Maisin, who utilized bacteriophages to treat staphylococcal skin sickness. The bacteriophages were infused into and around carefully opened injuries, and the creators detailed relapse of the contaminations inside 24 to 48 h. A few likewise encouraging examinations followed, and supported by these early outcomes, d'Herelle and others proceeded with investigations of the remedial utilization of phages (e.g., d'Herelle utilized different phage arrangements to treat a great many individuals having cholera and additionally bubonic plague in India). Moreover, a few organizations started dynamic commercial creation of phages against different bacterial microbes.

\subsection{DEVELOPMENT AND APPLICATION OF PHAGE- DERIVED LYTIC PROTEINS}

Among the most encouraging of advances in phage treatment is the detachment of phageencoded lytic catalysts, which are practically like the antimicrobial eukaryotic chemical lysozyme. Qualities for phage lytic chemicals are communicated by the bacterial host during the lytic cycle and help the phage by hydrolysing the phone divider to deliver viral descendants. The disclosure and investigation of these proteins opens the opportunities for the advancement of novel phage-based drugs.

Two significant protein classes are utilized by most of phage species during the lysis of the bacterial host. One of which is the transmembrane protein holin and the other is a peptidoglycan cell divider hydrolase called endolysin (lysin). These two proteins cooperate in setting off the lysis of the bacterial cell. The holin protein goes about as an atomic "clock" in the lytic cycle.

Adding to the allure of lysins as antibacterial specialists, it is generally viewed as far-fetched that microorganisms will develop protection from lysins because of the way that they target locales on the peptidoglycan cell divider basic for bacterial practicality. Designed recombinant phage lytic proteins would be far simpler to mass deliver and regulate than arrangements of genuine phage, which can be restricted by a short timeframe of realistic usability, evacuation by the reticuloendothelial arrangement of the host, and the potential for creating killing antibodies. Future potential for phage lysin application incorporates blend treatment of lysins related to antimicrobials, which has been demonstrated to be more powerful than anti-toxins or lysins alone against microorganisms like MRSA and C. difficile in mice.

\subsection{POTENTIAL ADVANTAGES OF BACTERIOPHAGE}

The most appealing quality of bacteriophage is their particularity of activity, i.e., their capacity to kill just the microorganism that they can perceive.

They have an exceptionally thin range of movement, which keeps away from the main issue rigorously identified with the anti-microbial organization, i.e., the impact on the whole microbiome with disposal of conceivably useful microorganisms, the abundance of auxiliary microbes and the rise of safe microbes.

It is felt that bacteriophage is essentially more secure and better endured, as they recreate just in the objective bacterium yet can't contaminate mammalian cells.

Utilizing the new practical, enormous scope DNA sequencing and DNA blend innovations, bacteriophage can be designed to have the option to conquer a few constraints of anti-toxin treatment. A genuine illustration of this is given by the proof that bacteriophages can scatter biofilm, a construction that makes diseases hard to destroy with standard anti-microbial treatment regardless of whether microorganisms are delicate to the regulated medication.

At long last, the utilization of bacteriophage may be more affordable than that of anti-infection agents whose objectives are multidrug-safe microorganisms.

\subsection{FACTORS THAT CAN LIMIT THE USE OF BACTERIOPHAGE}

Rise of bacterial opposition against bacteriophages is conceivably conceivable, as microbes have or can foster a few components to forestall viral contaminations. Among these are stowing away, change or loss of receptor, discharge of substances that forestall phage grip to the bacterial microorganism, enactment of measures for hindering phage DNA infusion into the phone and hindrance of phage replication and delivery.

Lysogenic phages join their DNA into the bacterial genome. Subsequently, they may be vehicles for level trade of hereditary material and assume a part in the dispersion of anti-microbial resistance genes (ARGs). Hypothetically, 


\section{International Journal of Engineering Applied Sciences and Technology, 2021 \\ Vol. 6, Issue 5, ISSN No. 2455-2143, Pages 318-326 \\ Published Online September 2021 in IJEAST (http://www.ijeast.com)}

because of transduction, new organisms or significantly more safe microorganisms can create.

Bacteriophages and their items are non-self-antigens, and it's anything but astounding that they can be perceived by the invulnerable framework and instigate reactions that can hypothetically lessen the advantage of bacteriophage organization.

\section{CONCLUSION}

Bacteriophages have a few attributes that make them conceivably alluring remedial specialists. They are (i) profoundly explicit and exceptionally successful in lysing designated pathogenic microbes, (ii) protected, as highlighted by their broad clinical use in Eastern Europe and the previous Soviet Association and the business offer of phages during the $1940 \mathrm{~s}$ in the US, and (iii) quickly modifiable to battle the development of recently emerging bacterial dangers. What's more, countless distributions, some of which are inspected in this minireview, propose that phages might be successful helpful specialists in chose clinical settings. Without a doubt, large numbers of these investigations don't satisfy the current thorough guidelines for clinical preliminaries there still stay numerous significant inquiries that should be tended to before lytic phages can be broadly embraced for restorative use. In any case, there is an adequate collection of information and an urgent enough need to discover elective treatment modalities against quickly arising, anti-infection safe microorganisms to warrant further examinations in the field of phage treatment.

Over the long run, the investigations regarding bacteriophages reached out from phage microscopic organisms communications to associations with nonbacterial cells, including cells of eukaryotes. These connections remember restricting of phages with explicit receptors for eukaryotic cells, transcytosis, and level quality exchange. Besides, the possible parts of bacterial infections in neurodegenerative illness and disease have additionally been investigated. Thinking about the amazing variety of phages and eukaryotes, more examinations are needed to recognize new instruments of collaborations and furthermore to clarify which association modes are normal and which are special. Not exclusively are bacteriophages being outstanding microorganisms yet they may likewise be utilized as examination instruments and important collection for biologic objective based medication advancement and medication conveyance frameworks. Accordingly, communications of bacterial infections with eukaryotic cells are current and significant examination subject.

\section{REFERENCES}

1. McGrath S and van Sinderen D (editors). (2007). Bacteriophage: Genetics and Molecular Biology (1st ed.). Caister Academic Press. ISBN 978-1-90445514-1.

2. "Novel Phage Therapy Saves Patient with MultidrugResistant Bacterial Infection". UC Health - UC San Diego. Retrieved 13 May 2018.

3. Suttle, Curtis A. (September 2005). "Viruses in the sea". Nature. 437 (7057): 356-361. doi:10.1038/nature04160. ISSN 0028-0836.

4. Jump up to: ${ }^{\text {a }}$ b Wommack, K. E.; Colwell, R. R. (2000). "Virioplankton: Viruses in Aquatic Ecosystems". Microbiology and Molecular Biology Reviews. 64 (1):

5. 69-114. doi:10.1128/MMBR.64.1.69-114.2000. PMC 98987. PMID 10704475

6. Hankin E. H. L'action bactericide des eaux de la Jumna et du Gange sur le vibrion du cholera. Ann. Inst. Pasteur 101896511

7. Samsygina G. A. and Boni E. G. Bacteriophages and phage therapy in pediatric practice. Pediatria 41984 6770

8. Van Helvoort T. Bacteriological and physiological research styles in the early controversy on the nature of the bacteriophage phenomenon. Med. Hist. 31992 243270

9. Twort F. W. An investigation on the nature of ultramicroscopic viruses. Lancet ii 19151241

10. Summers W. C. Felix d'Herelle and the origins of molecular biology. 1999 Yale University Press New Haven, Conn

11. D'Herelle F. Sur un microbe invisible antagoniste des bacilles dysentériques. C. R. Acad. Sci. (Paris) 165 1917373375

12. Bordet J. and Ciuca M. Remarques sur l'historique de recherches concernant la lyse microbienne transmissible. Compt. Rend. Soc. Biol. 841921745 747. 12. Twort F. W. Researches on dysentery. Br. J. Exp. Pathol. 11920237243

13. Wikoff WR, Liljas L, Duda RL, Tsuruta H, Hendrix RW, Johnson JE.

14. Topologically linked protein rings in the bacteriophage HK97 capsid. Science. 2000;289:21292133.

15. Wikoff WR, Conway JF, Tang J, Lee KK, Gan L, Cheng N, et al. Time-resolved molecular dynamics of bacteriophage HK97 capsid maturation interpreted by 


\section{International Journal of Engineering Applied Sciences and Technology, 2021 \\ Vol. 6, Issue 5, ISSN No. 2455-2143, Pages 318-326 \\ Published Online September 2021 in IJEAST (http://www.ijeast.com)}

electron cryo-microscopy and X-ray crystallography. Journal of Structural Biology. 2006;153(3):300-306.

16. Huet A, Conway JF, Letellier L, Boulanger P. In vitro assembly of the $\mathrm{T}=13$ procapsid of bacteriophage $\mathrm{T} 5$ with its scaffolding domain. Journal of Virology.

17. 2010;84:9350-9358. DOI: 10.1128/JVI.00942-10.

18. Veesler D, Quispe J, Grigorieff N, Potter CS, Carragher B, Johnson JE.

19. Maturation in action: CryoEM study of a viral capsid caught during expansion. Structure. 2012;20:13841390 .

20. Baker TS, Olson NH, Fuller SD. Adding the third dimension to virus life cycles: Three-dimensional reconstruction of icosahedral viruses from cryoelectron micrographs. Microbiology and Molecular Biology Reviews. 1999;63(4):862-922.

21. Tavares P. The bacteriophage head-to-tail interface. Sub-Cellular Biochemistry. 2018;88:305-328. DOI: 10.1007/978-981-10-8456-0_14

22. Veesler D, Cambillau C. A common evolutionary origin for tailed bacteriophage functional modules and bacterial machineries. Microbiology and Molecular Biology Reviews. 2011;75:423-433

23. Davidson AR, Cardarelli L, Pell LG, Radford DR, Maxwell KL. Long noncontractile tail machines of bacteriophages. Advances in Experimental Medicine and Biology. 2012;726:115-142.

24. Veesler D, Robin G, Lichière J, Auzat I, Tavares P, Bron P, et al. Crystal structure of bacteriophage SPP1 distal tail protein (gp19.1): A baseplate hub paradigm in Gram-positive infecting phages. The Journal of Biological Chemistry.

25. 2010;285:36666-36673

26. Xiang Y, Morais MC, Cohen DN, Bowman VD, Anderson DL, Rossmann MG. Crystal and cryoEM structural studies of a cell wall degrading enzyme in the bacteriophage phi29 tail. Proceedings of the National Academy of Sciences of the United States of America. 2008;105(28):9552-9557.

27. Barr JJ, Auro R, Furlan M, Whiteson KL, Erb ML, Pogliano J, Stotland A, Wolkowicz R, Cutting AS, Doran KS, Salamon P, Youle M, Rohwer F

28. Proc Natl Acad Sci U S A. 2013 Jun 25; 110(26):10771-6.

29. Wright A, Hawkins CH, Anggård EE, Harper DR. A controlled clinical trial of a therapeutic bacteriophage preparation in chronic otitis due to antibiotic-resistant Pseudomonas aeruginosa; a preliminary report of efficacy. Clin

30. Otolaryngol. 2009;34:349-357.
31. Yosef I, Manor M, Kiro R, Qimron U. Temperate and lytic bacteriophages programmed to sensitize and kill antibiotic-resistant bacteria. Proc Natl Acad Sci USA. 2015;112:7267-7272.

32. Roach DR, Donovan DM. Antimicrobial bacteriophage-derived proteins and therapeutic applications. Bacteriophage. 2015;5:e1062590.

33. Oliveira H, Vilas Boas D, Mesnage S, Kluskens LD, Lavigne R, Sillankorva S, Secundo F, Azeredo J. Structural and Enzymatic Characterization of ABgp46, a Novel Phage Endolysin with Broad AntiGram-Negative Bacterial Activity. Front Microbiol. 2016;7:208

34. Lood R, Winer BY, Pelzek AJ, Diez-Martinez R, Thandar M, Euler CW, Schuch R, Fischetti VA. Novel phage lysin capable of killing the multidrugresistant gramnegative bacterium Acinetobacter baumannii in a mouse bacteremia model. Antimicrob Agents Chemother. 2015;59:1983-1991.

35. Twort F W. Researches on dysentery. Br J Exp Pathol. 1920;1:237-243.

36. Van Helvoort T. Bacteriological and physiological research styles in the early controversy on the nature of the bacteriophage phenomenon. Med Hist. 1992;3:243-270.

37. Vieu J F, Guillermet F, Minck R, Nicolle P. Donnees actuelles sur les applications therapeutiques des bacteriophages. Bull Acad Natl Med. 1979;163:61.

38. Weber-Dabrowska B, Dabrowski M, Slopek S. Studies on bacteriophage penetration in patients subjected to phage therapy. Arch Immunol Ther Exp. 1987;35:563-568.

39. Weber-Dabrowska B, Zimecki M, Mulczyk M. Effective phage therapy is associated with normalization of cytokine production by blood cell cultures. Arch Immunol Ther Exp. 2000;48:31-37.

40. Yao J D C, Moellering R C., Jr . Antimicrobial agents. In: Murray P R, Baron E J, Pfaller M A, Tenover F C, Yolken R H, editors. Manual of clinical microbiology. 7th ed. Washington, D.C.: American Society for Microbiology; 1995. pp. 1474-1504. 